Check for updates

Cite this: Mater. Chem. Front. 2020, 4, 3190

Received 14th July 2020, Accepted 25th August 2020

DOI: $10.1039 / \mathrm{d} 0 \mathrm{qm} 00484 \mathrm{~g}$

rsc.li/frontiers-materials

\section{Pyrene-based metallocycles and metallocages: more than fluorophores}

\author{
Xu-Qing Wang, ${ }^{a}$ Qing-Hui Ling, ${ }^{a}$ Wei Wang*a and Lin Xu (D) *ab
}

\begin{abstract}
Attributed to their synthetic accessibility, unique structural and intriguing photophysical features, pyrene moieties have recently been introduced into supramolecular coordination complexes (SCCs) such as metallocycles and metallocages as either functional groups or key panels. The resultant pyrene-based SCCs displayed not only attractive emission properties but also impressive binding abilities towards diverse guests, endowing them with wide applications in sensing, host-guest chemistry, light harvesting etc. In this review, a comprehensive summary of pyrene-based metallocycles and metallocages is presented, and the emphasis will be on the intriguing photophysical features and unique host-guest chemistry that the pyrene moieties bring to the SCCs.
\end{abstract}

\section{Introduction}

During the past few decades, on the basis of the relatively rigid yet dynamic metal-ligand coordination bonds, coordinationdriven self-assembly has evolved as a general and powerful strategy towards the construction of diverse delicate and elegant two-dimensional (2D) and three-dimensional (3D) supramolecular coordination complexes (SCCs) such as metallocycles and metallocages. ${ }^{1}$ Taking advantage of their well-defined geometry and well-tuned cavities as well as well-arranged functional groups

\footnotetext{
${ }^{a}$ Shanghai Key Laboratory of Green Chemistry and Chemical Processes, School of Chemistry and Molecular Engineering, East China Normal University, 3663 North Zhongshan Road, Shanghai 200062, People's Republic of China. E-mail: wwang@chem.ecnu.edu.cn, lxu@chem.ecnu.edu.cn

${ }^{b}$ State Key Laboratory of Fine Chemicals, Dalian University of Technology, Dalian 116024, P. R. China
}

within their skeletons, the resultant SCCs have shown wide applications in diverse fields such as host-guest chemistry, catalysis, drug delivery, functional materials, and so on. ${ }^{2}$ Recently, increasing interest in the construction of fluorescent SCCs has been witnessed since they can serve as privileged platforms for sensing study, the mimicking of natural photosynthetic processes, the fabrication of photoelectric devices, etc. ${ }^{3}$ In general, the fluorophores can be introduced as either functional groups that are attached to the key building blocks or key panels that are incorporated into the main skeletons of the targeted fluorescent SCCs.

As one of the most common and useful fluorophores, pyrene is an excellent candidate for the construction of novel fluorescent SCCs. ${ }^{4}$ First of all, the synthetic accessibility of pyrene derivates with diverse functional groups and well-defined structural features lays the foundation for the construction of

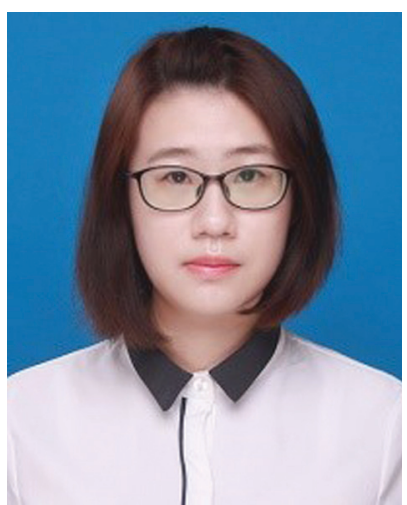

Xu-Qing Wang
Xu-Qing Wang received her $B S$ degree in chemistry from Northwest $A$ \& $F$ University in 2014. She obtained her PhD degree from East China Normal University in 2019 under the supervision of Prof. Hai-Bo Yang. Then she joined Professor Yang's group as a Postdoctoral Fellow in June 2019. Her current research interest is focused on well-controlled self-assembly of supramolecular coordination architectures.

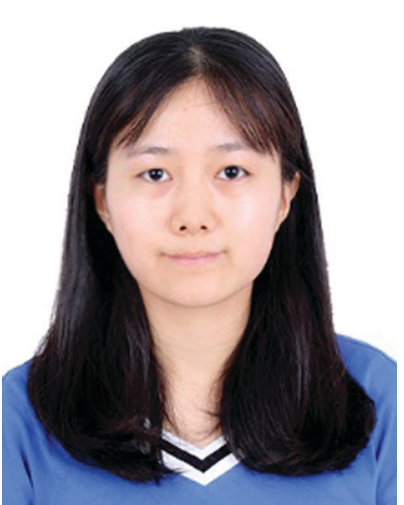

Qing-Hui Ling
Qing-Hui Ling received her BS degree in applied chemistry from Anhui University of Science and Technology in 2019. She is now pursuing her MS degree in Prof. Hai-Bo Yang's group at East China Normal University. Her research interests focus on the design and synthesis of functional fluorescent metallacages. 
diverse SCCs with pyrene moieties either as functional groups or building blocks; secondly, compared with other fluorophores, pyrene derivates usually displayed intriguing photophysical properties, such as high fluorescence quantum yield, relatively long excited-state lifetime, unique excimer emission etc. Notably, the fluorescence bands for the monomer and excimer of pyrene derivates reveal exceptional distinction and, moreover, their excitation spectra are very sensitive toward the changes of microenvironments. ${ }^{5}$ Taking advantage of all these attractive photophysical features, pyrene derivates can serve as versatile fluorophores for the incorporation of expected photophysical functions into the resultant SCCs. Last but not least, the relatively large conjugated $\pi$-electron-rich surface of pyrene derivates makes them excellent candidates as panels for the construction of SCCs with well-defined and confined pockets for the investigations of host-guest chemistry. During the past few years, a growing number of reports on the construction of pyrene-based SCCs has been witnessed, and thus it is time to summarize these developments and achievements. Herein, divided by the different types of SCC cores, pyrene-based 2D metallocycles and 3D metallocages will be discussed, with an emphasis on the intriguing photophysical features and unique host-guest chemistry that the pyrene moieties bring to the SCCs.

\section{Pyrene-based 2D metallocycles}

Aiming at mimicking natural light harvesting systems with circular dye arrays, Würthner and coworkers ${ }^{6}$ reported the construction of a well-defined molecular square 2 , in which sixteen pyrene and four perylene bisimide chromophores are arranged in a circular way (Scheme 1). In the resultant metallocycle, the outer pyrene moieties served as antenna dyes, from which highly efficient and fast photo-induced energy transfer as well as very fast and efficient electron transfer to the inner perylene bisimide chromophores was demonstrated. Such

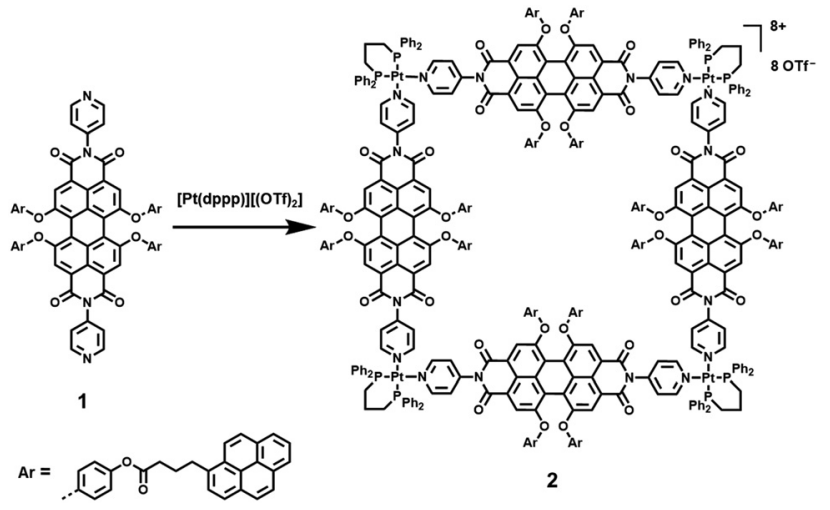

Scheme 1 The construction of molecular square 2 with sixteen pyrene and four perylene bisimide chromophores arranged in a circular way.

photophysical processes were clearly confirmed by the combination of steady-state and time-resolved emission as well as femtosecond transient absorption studies. More impressively, compared with the free ligand $\mathbf{1}$, the metallocycle 2 revealed substantially faster and more efficient electron-transfer processes, making it a novel monodisperse nanoaggregate with well-defined multiple-chromophore arrangements.

On the basis of the coordination-driven self-assembly strategy, by employing various pyrene-modified ligands, Yang and coworkers ${ }^{7}$ demonstrated a simple and highly efficient approach for the construction of multipyrene hexagonal metallocycles with well-defined shape and size in 2013. As shown in Scheme 2, a mixture of pyrene-functionalized $120^{\circ} \mathrm{Pt}$ (II) acceptor 3 with a $120^{\circ}$ or $180^{\circ}$ dipyridyl donor resulted in the formation of corresponding multipyrene hexagons 4 or 5 with three or six pyrene moieties, respectively. In addition, the combination of pyrene-functionalized $120^{\circ}$ dipyridyl acceptor 6 and a $120^{\circ}$ or $180^{\circ} \mathrm{Pt}$ (II) acceptor could also give rise to similar tris- and hexakis(pyrene) hexagonal metallocycles 7 and $\mathbf{8}$, respectively. Interestingly, preliminary spectroscopic study of

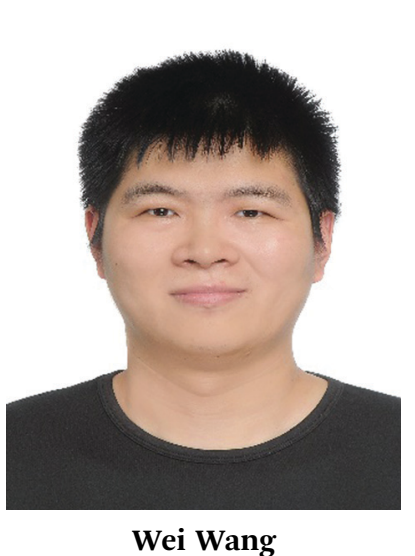

Wei Wang obtained his BSc degree from Sichuan University in 2011 and PhD degree from the East China Normal University in 2016 under the supervision of Prof. Hai-Bo Yang. He then joined Prof. A. Dieter Schlüter's group at ETH Zürich to pursue postdoctoral study (2016-2019). After that, he has become a research professor (Zijiang Young Scholar) at East China Normal University. His research interest includes interlocked macromolecules and topological chirality.

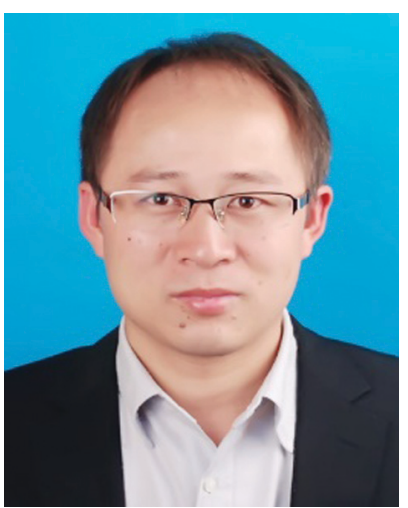

Lin Xu
Lin $X u$ received his $P h D$ degree in Chemistry from the East China University of Science and Technology (ECUST, Shanghai) in 2012 under the supervision of Professor Xuhong Qian. Subsequently, he joined the East China Normal University (ECNU, Shanghai) as an assistant professor and was promoted to an associate professor and a full professor in 2014 and 2018, respectively. He carried out twoyears postdoctoral research at the

University of Cambridge with Prof. Jonathan Nitschke during 2015-2017. His research interests focus mainly on supramolecular fluorescent chemistry. 

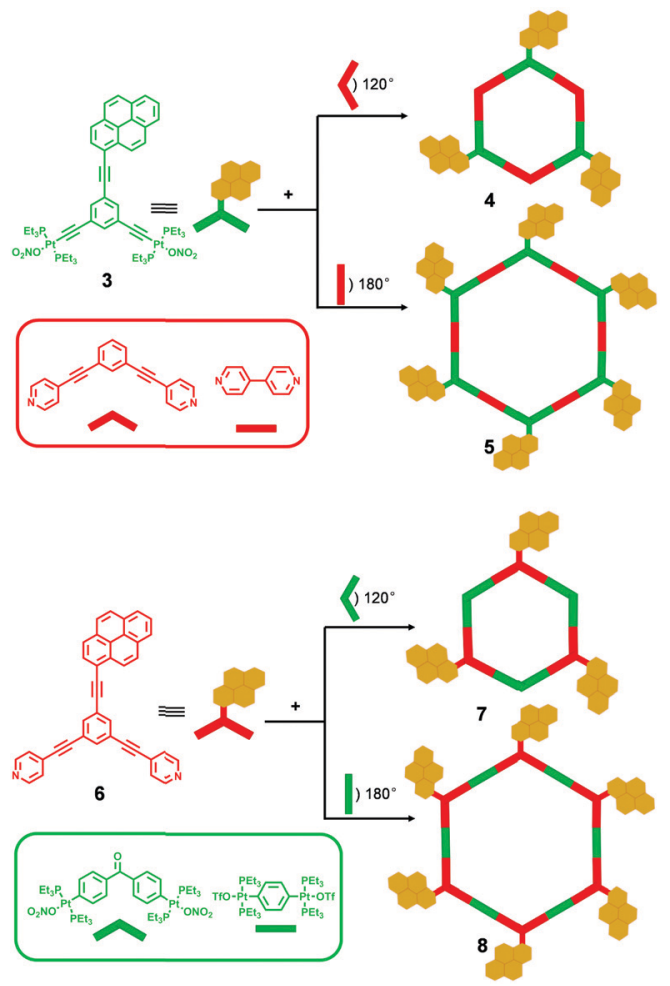

Scheme 2 Coordination-driven self-assembly of multipyrene hexagonal metallocycles 4, 5, 7, and 8 .

these resultant hexagonal metallocycles revealed dramatically different emission behaviours. For instance, hexagons 7 and 8 displayed a longer fluorescence emission band at $\lambda_{\max } 550 \mathrm{~nm}$ in $\mathrm{CH}_{2} \mathrm{Cl}_{2}$, which corresponded to the excimer emission of the pyrene chromophore. However, hexagons 4 and 5 could not form excimers at the same conditions. The results indicated that the combination mode of building blocks played an important role in the excimer formation of the resulting selfassemblies, which might be reasonably explained by the varied

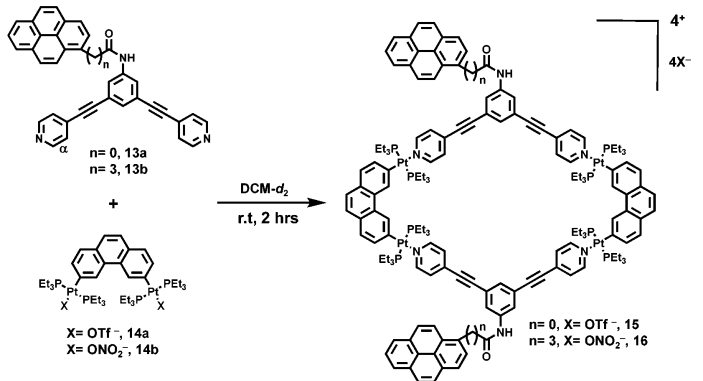

Scheme 4 Synthesis of pyrene-functionalized molecular rhomboids 15 and 16 .

charge densities of the resultant hexagons originating from the different combinations. Furthermore, by employing the same directional metal-ligand bonding strategy, the same group ${ }^{8}$ reported a series of pyrene-functionalized metallodendrimers 11 and 12 derived from pyrene-containing $120^{\circ} \mathrm{Pt}$ (II) acceptors (3 and 9) and $60^{\circ}$ dendritic donors 10 (Scheme 3). Notably, compared to the pyrene-containing precursors, improved fluorescence quantum yields of the corresponding pyrenemodified dendrimers were observed, which might be due to the fact that the steric hindrance of dendrons inhibited the aggregation of pyrenes.

Similarly, Stang et al. ${ }^{9}$ prepared two rhomboids 15 and 16 by mixing pyrene-functionalized $120^{\circ}$ donor 13 and $60^{\circ} \mathrm{Pt}($ II) acceptor 14 (Scheme 4) via [2+2] self-assembly. Due to the existence of pyrene groups, both rhomboids were emissive and exhibited excimer emission bands, which derived from intermolecular interactions. Additionally, it was found that both the length of the spacers between the metallocycles and pyrene units and the solvent polarity had a great influence on the emission properties. For instance, as revealed by the emission spectra, rhomboids 15 and 16 displayed very different emission bands in sole $\mathrm{CH}_{2} \mathrm{Cl}_{2}$ solution. Meanwhile, the increase of the fraction of $\mathrm{CH}_{3} \mathrm{OH}$ in $\mathrm{CH}_{2} \mathrm{Cl}_{2}$ could further remarkably modulate the emission behaviours of both rhomboids.
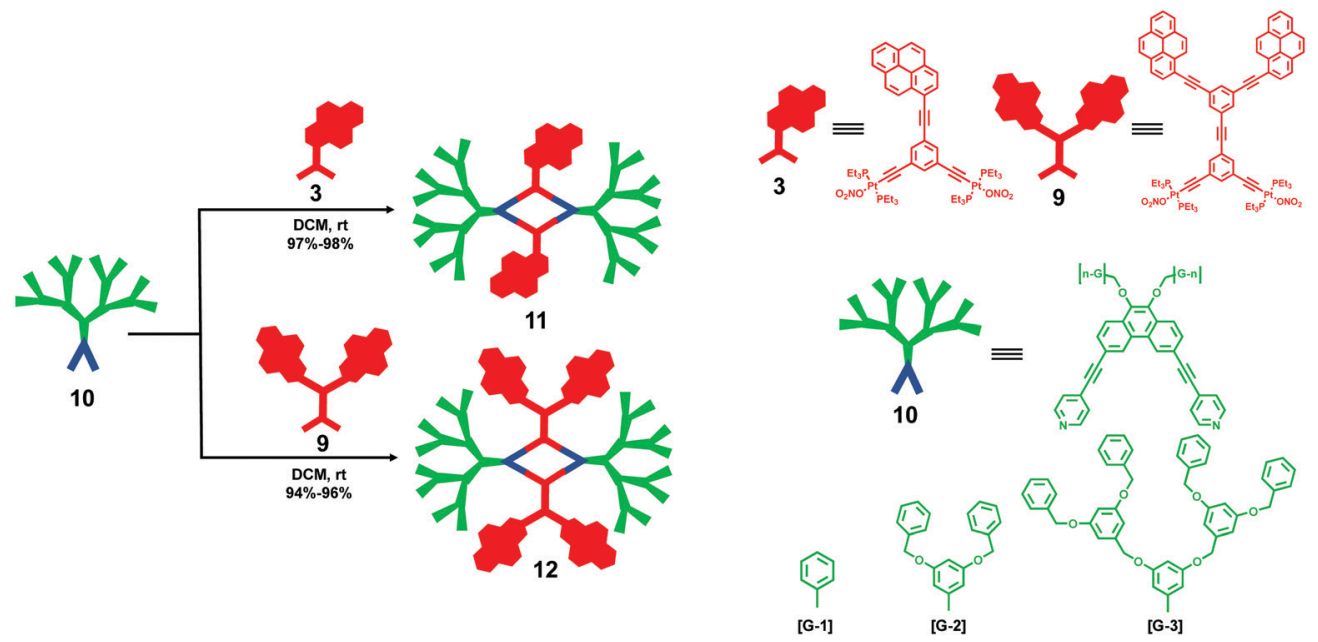

Scheme 3 Coordination-driven self-assembly of multipyrene hexagonal metallocycles 11 and 12 . 


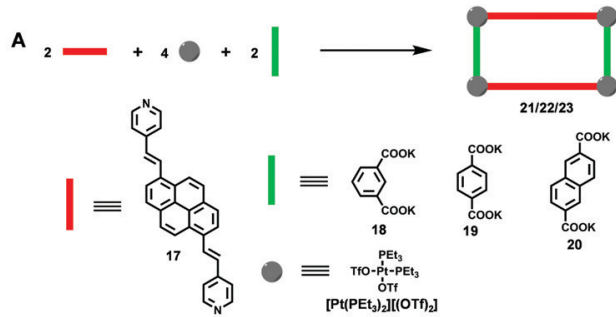

B

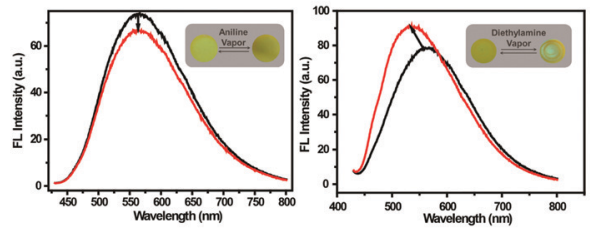

Fig. 1 The construction of pyrene-based metallocycles 21-23 via coordination-driven self-assembly $(A)$ and the sensing performance of 22-based fluorescent films towards aniline (left) and diethylamine (right) (B). Adapted with permission from ref. 10. (Copyright 2019 American Chemical Society.)

As shown in Fig. 1, the three-component coordinationdriven self-assembly of pyrene-cored dipyridyl donor 17 , a $90^{\circ}$ di-Pt(II) acceptor $\left[\mathrm{Pt}\left(\mathrm{PEt}_{3}\right)_{2}\right]\left[(\mathrm{OTf})_{2}\right]$ and dicarboxylates 18-20 resulted in the formation of three pyrene-based metallocycles 21-23, respectively, which exhibited enhanced solubility in common organic solvents compared with the pyrene-cored ligand 17. The resultant three metallocycles displayed similar emission properties in the solution state, but different emission wavelengths in the aggregated states. Interestingly, it was found that the solution emission of these metallocycles could be well-tuned through the modulation of the temperature and solvent, which is expectable since both factors could remarkably influence the aggregation states of the metallocycles mainly formed through the intermolecular $\pi-\pi$ interaction between the pyrenyl moieties. Notably, taking advantage of the excellent photochemical stability, a homemade aromatic amine sensing platform with ligand 17-based or metallocycle 22-based fluorescent films as the core structure was built. More importantly, regarding the response speed and recovery time, the metallocycle 22-based one revealed superior sensing performance (Fig. 1B), indicating that the formation of the metallocycles contributed a remarkable enhancement effect in the film state. ${ }^{10}$

In 2019, Stang et al. ${ }^{11}$ developed a new strategy for the construction of a cross-linked supramolecular polymer based on platinum(II) metallocycles. As shown in Fig. 2, selfassembled [2+2] metallocycle 26 was prepared by mixing pyrene-functionalized donor 24 with $180^{\circ}$ di-Pt(II) acceptor 25, which contained two pyrene moieties at the periphery. Attributed to the existence of $\mathrm{C}-\mathrm{H} \cdots \pi$ interactions, host-guest interactions between the metallocycle core and the pyrene periphery were observed, as indicated by solid-state singlecrystal structure and solution-state NMR study, respectively. Moreover, based on such an interesting driving force, a crosslinked supramolecular polymer was spontaneously formed in

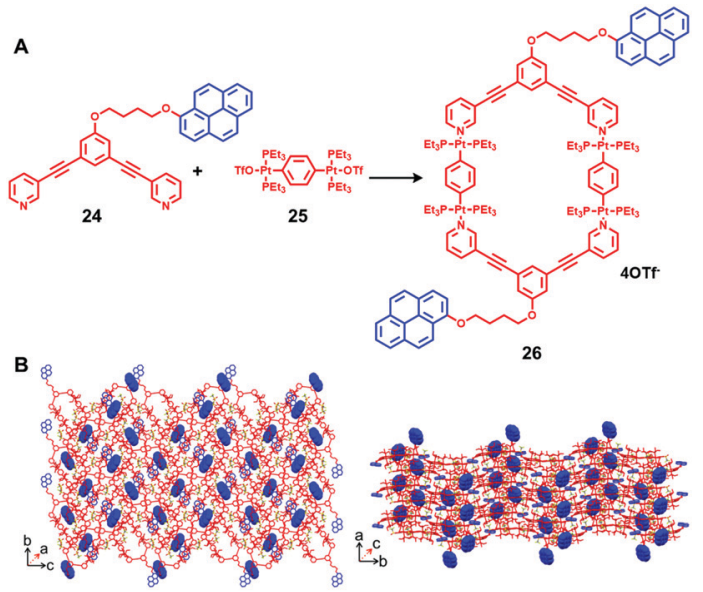

Fig. 2 The construction of metallocycles 26 bearing two pyrene moieties via coordination-driven self-assembly $(\mathrm{A})$ and the single-crystal structure of the cross-linked supramolecular polymer of 26 (B). Adapted with permission from ref. 11. (Copyright 2019 American Chemical Society.)

both the solid and solution state. Similar to other platinum metallocycle-based supramolecular polymers, ${ }^{12}$ the resultant cross-linked supramolecular polymer displayed interesting thermo-responsiveness and ion responsiveness. For instance, reversible thermo-induced phase transitions of the gel-like viscous liquids prepared from a highly concentrated solution of 26 were observed. In addition, attributed to the breaking and reforming of the $\mathrm{Pt}-\mathrm{N}$ bonds in metallocycle 26, a reversible transition between the gel-like supramolecular polymer and turbid solution was successfully achieved through the addition and removal of bromide anions.

Based on their continuous interest in poly-N-heterocyclic carbenes (NHCs), ${ }^{13}$ in 2017, Peris and coworkers ${ }^{14}$ demonstrated the preparation of a novel dimetallic complex 28 by mixing pyrene-linked di-NHC ligand 27 with nickelocene. Then, based on a metal-directed self-assembly strategy, in the presence of $\mathrm{AgBF}_{4}$, the reaction of 28 with pyrazine or $4,4^{\prime}$-bipyridine resulted in the successful synthesis of nickel-cornered metallorectangles 29 and 30, respectively (Scheme 5). The resultant molecular rectangles were then tested to serve as receptors for the recognition of polycyclic aromatic hydrocarbons (PAHs). Due to the varied length of one of their sides, rectangle 29 could host one guest molecule within its cavity, whereas rectangle $\mathbf{3 0}$ was able to encapsulate up to two guest molecules, and the binding affinities strongly depended on the dimensional matching between the metallocycle hosts and guests. Notably, both rectangles could be used as efficient PAH scavengers in heptane though the formation of insoluble host-guest complexes.

Starting from the same pyrene-linked di-NHC ligand, the same group ${ }^{15}$ further prepared a palladium-cornered metallosquare 31 in 2019 via the metal-directed self-assembly strategy. Due to the existence of the flat polyaromatic surface of the four pyrene moieties, the resultant $3 \mathrm{D}$ cubic box with a large internal cavity could encapsulate both $\mathrm{C}_{60}$ and $\mathrm{C}_{70}$ fullerenes. The molecular structures of 31, $\mathrm{C}_{60} @ 31$ and $\mathrm{C}_{70} @ 31$ were determined by single-crystal X-ray diffraction (Fig. 3). More 


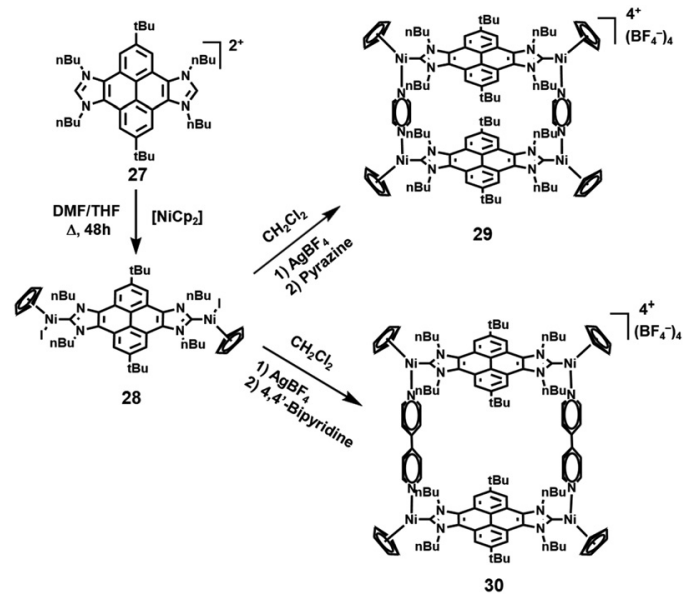

Scheme 5 The synthesis of nickel-cornered metallo-rectangles 29 and $\mathbf{3 0}$.

importantly, as revealed by these solid-state structures, the resulting metallo-square was size-flexible and adaptable, which was able to adapt its size to the size of guest molecules. Furthermore, taking advantage of the excellent spin-converting properties of fullerenes, Peris et al. employed both inclusion complexes $\mathrm{C}_{60} @ 31$ and $\mathrm{C}_{70} @ 31$ as photochemically stable photosensitizers to efficiently generate singlet oxygen, which could oxidize a series of cyclic and acyclic alkenes at room temperature. ${ }^{16}$ In addition, considering that the distance between the palladium atoms of metallosquare $\mathbf{3 1}$ is about $13 \AA$, which is large enough to host three polyaromatic guests, metallo-square 31 was further employed for the encapsulation of three heteroguests including two electron-rich PAH molecules such as pyrene, triphenylene or coronene and one electron-poor $N, N^{\prime}$-dimethyl-naphthalene-tetracarboxy diimide (NTCDI) molecule, giving rise to the formation of interesting quintuple D-A-D-A-D stacks (Fig. 4). ${ }^{17}$

Recently, as an extension of their previous work, Peris et al. ${ }^{18}$ demonstrated the synthesis of a novel tetragold metallo-rectangle 34 by the reaction of the pyrene-bis-imidazolydene-gold(I)
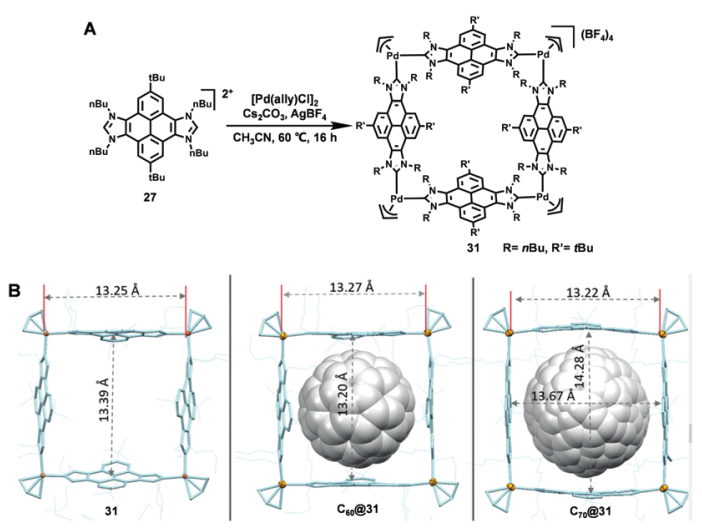

Fig. 3 The preparation of palladium-cornered metallosquare $31(\mathrm{~A})$ and the X-ray diffraction structures of 31 (left), $C_{60} @ 31$ (middle), and $C_{70} @ 31$ (right) (B). Adapted with permission from ref. 15. (Copyright 2019 Wiley$\mathrm{VCH}$.)
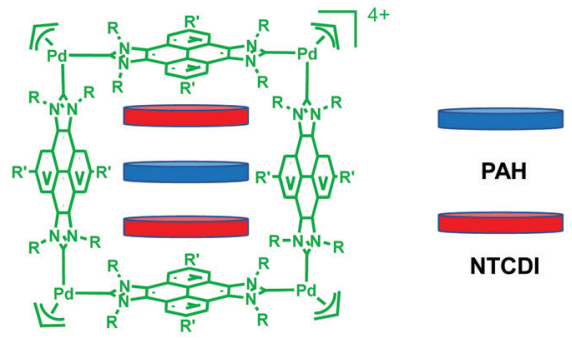

$[31 \supset(\mathrm{PAH}+2 \mathrm{NTCDI})]^{4+}$

Fig. 4 The formation of the quintuple $D-A-D-A-D$ stacks based on palladium-cornered metallosquare 31 .

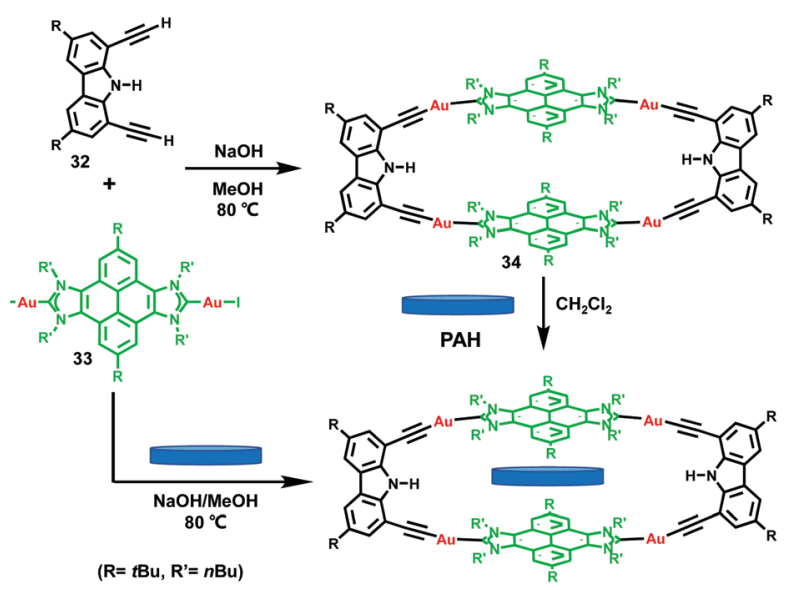

Fig. 5 The synthesis of the tetragold metallo-rectangle 34 and its complexes with diverse PAHs.

complex 33 and di-tert-butyl-diethynyl-carbazole 32 in the presence of $\mathrm{NaOH}$ as a base. Due to the existence of two cofacial pyrene panels separated by almost exactly $7 \AA$ within its structure, the resultant tetragold metallo-rectangle was able to encapsulate a series of PAHs, such as anthracene, pyrene, triphenylene, perylene, coronene and corannulene (Fig. 5). It was found that for the planar PAH guests, the binding affinities increased with the number of electrons, which derived from dimensional matching. Meanwhile, for a bowl-shaped guest such as corannulene, a mutual induced-fit arrangement in the inclusion complex with a remarkable compression of the guest molecule and the concomitant expansion of the metallo-host was revealed, which was accompanied by a reduced binding affinity.

\section{Pyrene-based 3D metallocages}

Similar to the cases of $2 \mathrm{D}$ metallocycles as described above, ${ }^{19}$ pyrene could also be introduced into $3 \mathrm{D}$ metallocages as functional groups that endowed novel photophysical properties such as attractive emission properties as described below to the resultant SCCs. For instance, Johnson and coworkers ${ }^{20}$ demonstrated the preparation of a novel class of polymer network, i.e. star PolyMOCs, in which metal-organic cages (MOCs) served as junctions that were cross-linked by polymer chains. 
Starting from bispyridine-functionalized tetra-arm star polymers 35 , small bispyridine ligands 36 , and $\mathrm{Pd}^{2+}$ ions, a three-component assembly approach led to the modular synthesis of star polyMOC gels with Fujita's famous $\mathrm{M}_{12} \mathrm{~L}_{24}$ MOCs as junctions (Fig. 6A). More importantly, by varying the amounts of the small bipyridine ligands and $\mathrm{Pd}^{2+}$ ions while keeping the concentration of polymer constant, a series of polyMOC gels with well-tailored structures, mechanical properties and dynamics was successfully constructed. In order to further install functionality into the resultant polyMOC gels, the pyrene-modified bispyridine ligand 37 was introduced as the fourth component to take part in the self-assembly process, which gave rise to novel fluorescent metallogels. As expected, upon the increase of the amount of the incorporated pyrenemodified bispyridine ligand, the fluorescence intensity of the corresponding metallogels is qualitatively proportional (Fig. 6B).
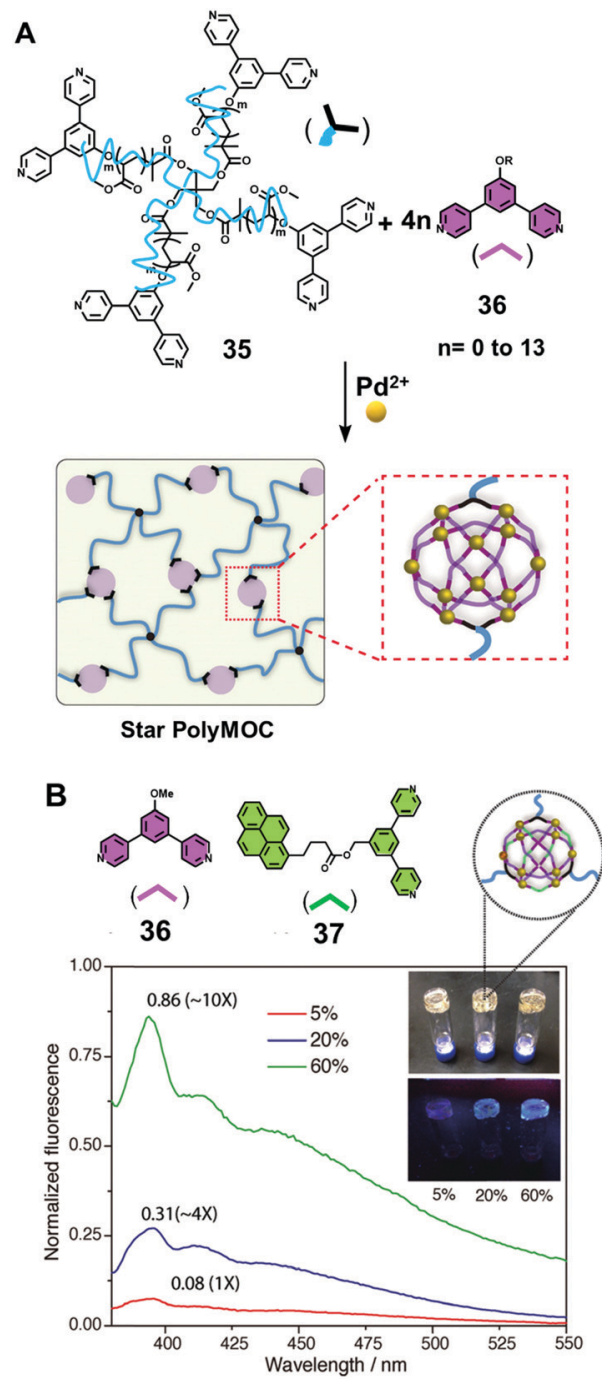

Fig. 6 The preparation of the star PolyMOCs via a three-component assembly approach (A) and the incorporation of pyrene moieties as functional groups (B). Adapted with permission from ref. 20. (Copyright 2017 Wiley-VCH.)
By using bis(aminophenyl)BODIPY and pyrene-appended formylpyridine as key subcomponents, a novel fluorescent metallo-supramolecular capsule $\mathbf{3 8}$ was successfully prepared by Nitschke and coworkers ${ }^{21}$ through the subcomponent selfassembly approach (Fig. 7A). In the resultant metallocage, the BODIPY moieties arranged along the edges and the pyrene moieties located at the vertices of the cage. Upon the binding of anionic guests such as acetate anions, a significant enhancement in the fluorescence of BODIPY was observed, while the pyrene fluorescence remained unchanged, which indicated that the binding of the anions was within the cage cavity. More interestingly, white light emission was observed when mixing metallocage 38 and perylene in a $1: 3$ ratio. Upon interacting with perylene, the emission intensity of the BODIPY moieties in the red region was remarkably enhanced, which played a key role in the generation of white emission (Fig. 7B). A control experiment, in which the mixture of the corresponding subcomponents as well as perylene only resulted in fluorescence in the blue and green regions rather than white emission, confirmed the importance of the cage architecture and its guest binding behaviour for white light emission.

Aiming at the design of novel fluorescent receptors for explosive detection, Mukherjee and coworkers ${ }^{22}$ demonstrated the construction of the first example of a platinum(II) tetragonal prism 41 through the two-component self-assembly of a new star-shaped pyrene-based planar $\mathrm{Pt}_{4}$ acceptor 39 and an amidebased "clip" donor 40 (Fig. 8). Attributed to the existence of highly conjugated tetraethynylpyrene moieties, the resultant selfassembled prism displayed an excellent fluorescence quenching response even at parts per billion (ppb) concentrations of TNT.

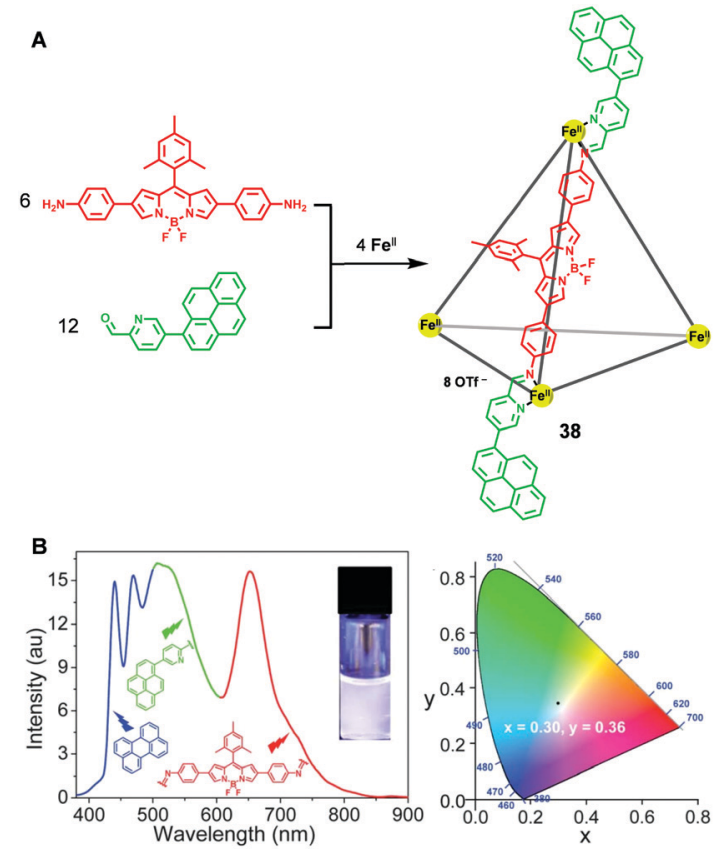

Fig. 7 The construction of the tetrahedral metallocage 38 via the subcomponent self-assembly approach (A) and the white light emission of the complex of the resultant metallocage and perylene (B). 


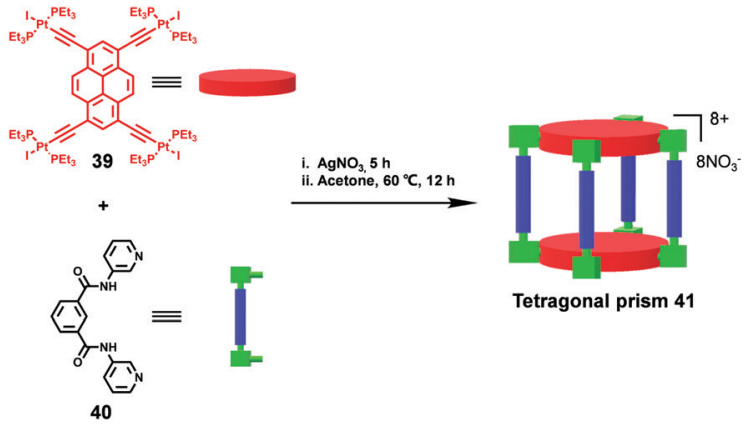

Fig. 8 The construction of the tetragonal prism 41 via coordinationdriven self-assembly for nitroaromatic sensing.

More importantly, compared with the planar tetratopic acceptor 39, superior selectivity of prism $\mathbf{4 1}$ towards the nitro-aromatic explosives (NAEs) was observed, thus highlighting the important role of the $\pi$-electron-rich confined nanopocket for NAE encapsulation and detection. It is worth noting that, by employing a $\mathrm{C}-\mathrm{H}$-activation-directed assembly approach, Jin and coworkers ${ }^{23}$ demonstrated the successful synthesis of a cuboid-shaped metallosupramolecular structure, in which two pyrene moieties also served as the floor and roof.

Through the self-assembly of aforementioned bis-nickelpyrene-di-imidazolylidene complex 28 with 1,3,5-tripyridyltriazine (TPT) in the presence of $\mathrm{AgBF}_{4}$, Peris et al. ${ }^{24}$ demonstrated the construction of a nickel-conjoined molecular prism 42 in 2018, whose molecular structure was determined by X-ray diffraction (Scheme 6). Similar to previously described metallosquare 31, the resultant metallocage was also size-flexible and adaptable, which could also encapsulate both $\mathrm{C}_{60}$ and $\mathrm{C}_{70}$ fullerenes. Moreover, as evaluated by the binding constants, the metallocage preferred complexing with $\mathrm{C}_{70}$ over $\mathrm{C}_{60}$, which was further confirmed by competitive experiments.

Considering the privileged role of pyrenes as planar and electron-rich panels for guest binding, two novel pyrene-edged

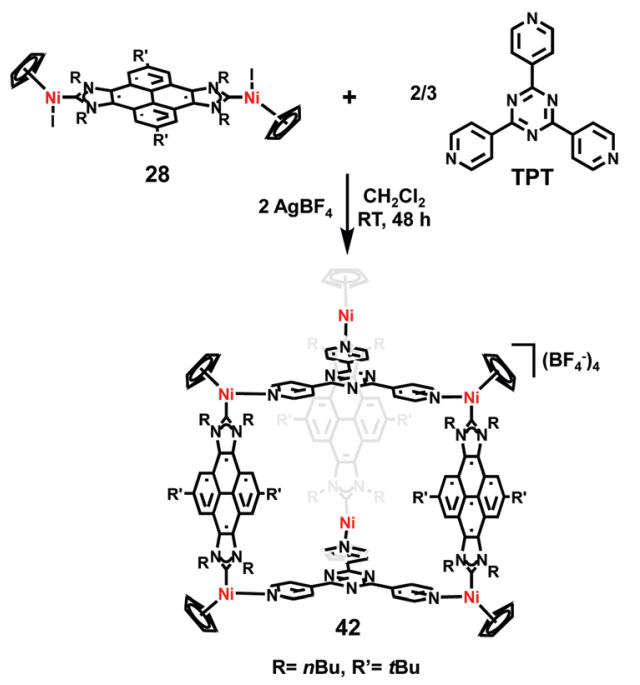

Scheme 6 The synthesis of nickel-cornered metallocage $\mathbf{4 2}$ for the encapsulation of fullerenes. metallocages 43 and 44 based on 1,6-pyrene and 2,7-pyrene scaffolds, respectively, were prepared by Nitschke and coworkers $^{25}$ though the subcomponent self-assembly approach (Scheme 7). As revealed by the ${ }^{1} \mathrm{H}$ NMR spectra, both metallocages consisted of three diastereomers, i.e. homochiral $T(\Delta \Delta \Delta \Delta / \Lambda \Lambda \Lambda \Lambda)$, heterochiral $C_{3}(\Delta \Delta \Delta \Lambda / \Lambda \Lambda \Lambda \Delta)$ and achiral $\mathrm{S}_{4}(\Delta \Delta \Lambda \Lambda)$. The ratios of these diastereomers for both metallocages were similar, both of which were close to the expected statistical distribution. Guest binding tests indicated that these two isomeric pyrene-edged metallocages displayed very different host-guest properties. For metallocage $\mathbf{4 3}$ based on a 1,6-pyrene scaffold, attributed to its well-enclosed cavity, it could serve as an excellent host for diverse guests ranging from large hydrophobic guests including fullerenes and PAHs to large, structurally complex natural products such as steroids. Interestingly, along with the fullerene binding processes, altered diastereomer distributions of $\mathbf{4 3}$ were observed, leading to the amplification of the diastereomers that can maximize the binding affinity. Meanwhile, in the case of metallocage 44 based on a 2,7-pyrene scaffold, due to the existence of an open cavity, it was unable to bind neutral guests. In a following paper, ${ }^{26}$ the same group further examined the important role of the cavity enclosure for strong guest binding. In this study, besides pyrene, other PAHs such as triphenylene, naphthalene, anthracene and chrysene were introduced as the edges, leading to a series of aromatic-paneled metallocages. By evaluating the binding affinities of these resultant metallocges towards diverse guests, metallocages with large, offset aromatic panels such as chrysene that could maximize the cavity enclosure were proven to be the most effective hosts.

By using two isomeric bis(3-aminophenyl)pyrene derivatives $\mathbf{A}$ and $\mathbf{B}$, rather than the isomeric bis(4-aminophenyl)pyrene derivatives described above, as key subcomponents, two unique
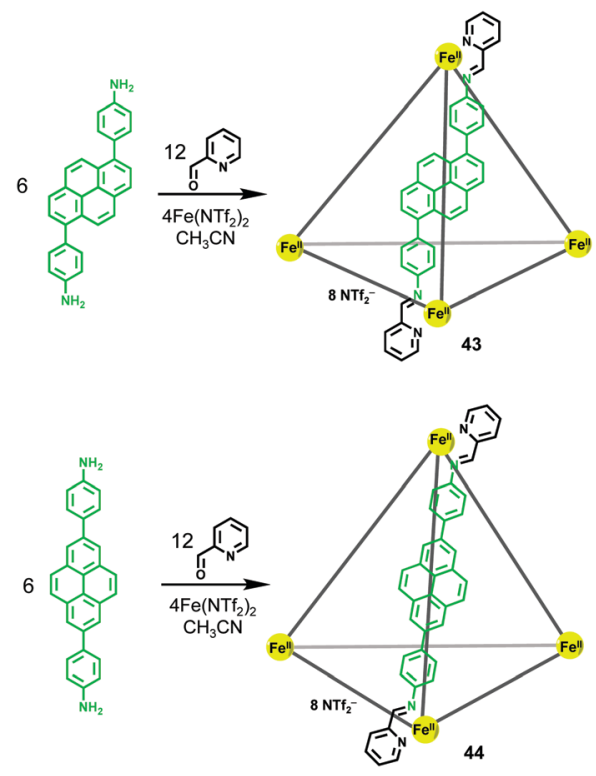

Scheme 7 The synthesis of pyrene-edged metallocages $\mathbf{4 3}$ and $\mathbf{4 4}$ via subcomponent self-assembly. 


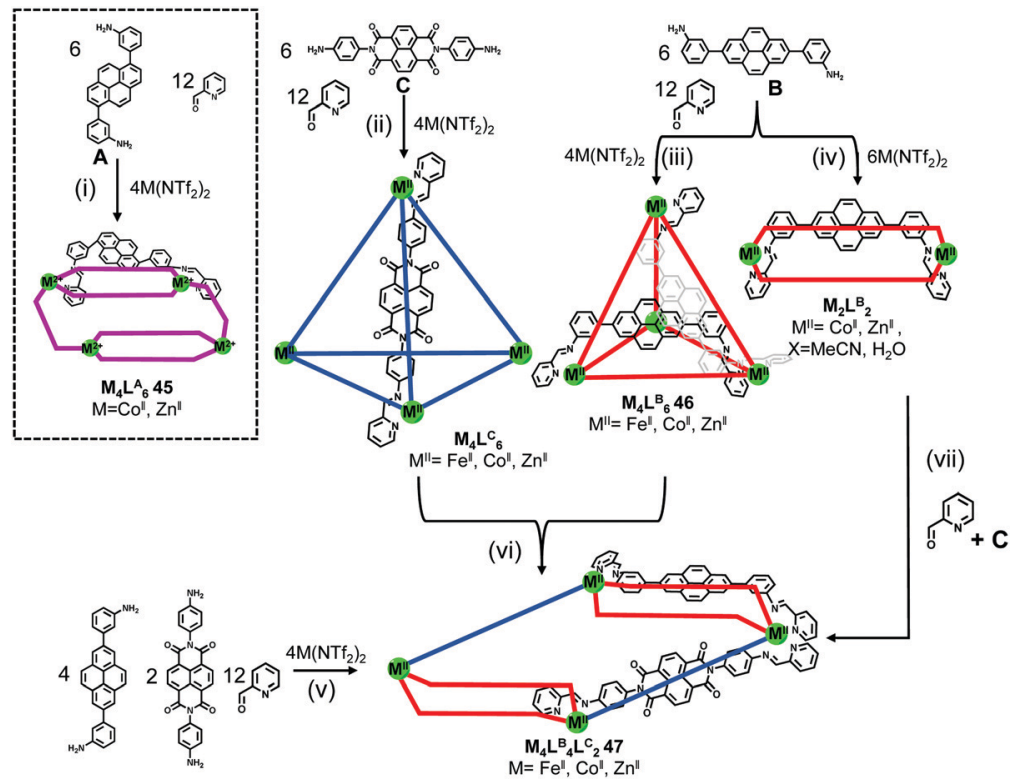

Scheme 8 The preparation of pyrene-based homeleptic and heteroleptic metallosupramolecular assemblies via subcomponent self-assembly.

metallosupramolecular structures, i.e. a $C_{2}$-symmetric $\mathrm{M}_{4}^{\mathrm{II}} \mathrm{L}_{6}$ assembly 45 with meridionally coordinated metal centers, and a $C_{3}$-symmetric self-included $\mathrm{M}_{4}^{\mathrm{II}} \mathrm{L}_{6}$ assembly 46 with facially coordinated metal centers $\left(\mathrm{M}^{\mathrm{II}}=\mathrm{Fe}^{\mathrm{II}}, \mathrm{Co}^{\mathrm{II}}\right.$, and $\left.\mathrm{Zn}^{\mathrm{II}}\right)$, were constructed by Nitschke and coworkers ${ }^{27}$ through the subcomponent self-assembly approach.

As revealed by the solid-state structures, face-to-face $\pi$-stacking interactions between the pyrene moieties were observed in both structures, which helped to stabilize the skeletons. Interestingly, the self-assembly of these two diamines, 2-formylpyridine (12 equiv.) and $\mathrm{Zn}\left(\mathrm{NTf}_{2}\right)_{2}$ in a $3: 3: 12: 4$ ratio resulted in the formation of a clean mixture of the homoleptic assemblies 45-Zn and 46-Zn, indicating a narcissistic self-sorting process that might be due to the geometrical differences as well as aforementioned favorable $\pi$-stacking within each individual metallosupramolecular structure. Furthermore, considering the favourable donor-acceptor stacking interactions between the pyrene units and naphthalenediimide (NDI) units, NDI-based diamine $\mathbf{C}$ was additionally chosen as a key subcomponent for the construction of heteroleptic metallosupramolecular assemblies. As expected, through either the direct subcomponent self-assembly approach (path v) or supramolecular transformation approach (path vi) as shown in Scheme 8, heteroleptic assemblies 47 were successfully prepared, from whose solid-state structure pyrene-pyrene-NDI stacks as the most favorable arrangements were identified.

\section{Conclusion and outlook}

During the past decades, more and more attention has been paid to the construction of pyrene-based SCCs including 2D metallocycles and 3D metallocages. Starting from pyrenefunctionalized building blocks or pyrene derivates themselves as key building blocks, diverse pyrene-based SCCs have been successfully constructed. For pyrene-based 2D metallocycles, more attention was paid to the investigation of their photophysical properties originating from the pyrene moieties. Meanwhile, in the case of pyrene-based 3D metallocages, due to the existence of well-defined cavities with pyrene panels, research interest mainly focusing on the host-guest chemistry of such novel metallo-hosts was witnessed. Attributed to the unique structural and intriguing photophysical features of the incorporated pyrene units, the resultant SCCs displayed not only attractive emission properties but also impressive binding abilities towards diverse guests, endowing them with wide applications in sensing, host-guest chemistry, light harvesting, and so on. Although great achievements have been made in this area, the research on this topic is still in its infancy, and more in-depth investigations are in great demand. To name a few, firstly, aiming at further biological applications, the design and synthesis of water-soluble and biocompatible pyrene-based SCCs will be of great importance. Secondly, considering the wide applications of pyrene-based materials for organic electronics, how to construct and employ novel pyrene-based SCCs for the fabrication of photoelectric devices will be worth being further explored. Thirdly, regarding pyrene-based metallohosts, the expansion of the scope of guests and the improvement of the selectivity are still needed, which will be essential for practical applications such as separation, sensing, controllable capture/release etc. Considering the great power of coordination-driven self-assembly in the facile and efficient construction of novel SCCs with increasing complexity, a bright future of pyrene-based metallocycles and metallocages will be anticipated.

\section{Conflicts of interest}

The authors declare no competing interest. 


\section{Acknowledgements}

X.-Q. W. is grateful to the Guanghua Excellent Postdoctoral Scholarship and China Postdoctoral Science Foundation (No. 2019M660084 and 2020T130198) for support. W. W. acknowledges the financial support sponsored by Shanghai Sailing Program (20YF1411500) and the Fundamental Research Funds for the Central Universities. L. X. acknowledges the financial support sponsored by the NSFC (No. 21922506, 21871092, and 21672070), the Fundamental Research Funds for the Central Universities, the Opening Projects of Shanghai Key Laboratory of Green Chemistry and Chemical Processes, and State Key Laboratory of Fine Chemicals (KF 1801).

\section{Notes and references}

1 (a) P. J. Stang and B. Olenyuk, Self-assembly, symmetry, and molecular architecture: coordination as the motif in the rational design of supramolecular metallacyclic polygons and polyhedra, Acc. Chem. Res., 1997, 30, 502; (b) D. Fiedler, D. H. Leung, R. G. Bergman and K. N. Raymond, Selective molecular recognition, $\mathrm{C}-\mathrm{H}$ bond activation, and catalysis in nanoscale reaction vessels, Acc. Chem. Res., 2005, 38, 349; (c) M. Fujita, M. Tominaga, A. Hori and B. Therrien, Coordination assemblies from a $\mathrm{Pd}(\mathrm{II})$-cornered square complex, Acc. Chem. Res., 2005, 38, 369; (d) S. Liu, Y.-F. Han and G.-X. Jin, Formation of direct metal-metal bonds from 16-electron "pseudo-aromatic" half-sandwich complexes Cp" $\mathrm{M}\left[\mathrm{E}_{2} \mathrm{C}_{2}\left(\mathrm{~B}_{10} \mathrm{H}_{10}\right)\right]$, Chem. Soc. Rev., 2007, 36, 1543; (e) R. Chakrabarty, P. S. Mukherjee and P. J. Stang, Supramolecular coordination: self-assembly of finite two- and three-dimensional ensembles, Chem. Rev., 2011, 111, 6810; $(f)$ M. J. Wiester, P. A. Ulmann and C. A. Mirkin, Enzyme mimics based upon supramolecular coordination chemistry, Angew. Chem., Int. Ed., 2011, 50, 114; $(g)$ T. R. Cook and P. J. Stang, Recent developments in the preparation and chemistry of metallacycles and metallacages via coordination, Chem. Rev., 2015, 115, 7001; (h) L. Xu, Y.-X. Wang, L.-J. Chen and H.-B. Yang, Construction of multiferrocenyl metallacycles and metallacages via coordination-driven selfassembly: from structure to functions, Chem. Soc. Rev., 2015, 44, 2148; (i) W. Wang, Y.-X. Wang and H.-B. Yang, Supramolecular transformations within discrete coordination-driven supramolecular architectures, Chem. Soc. Rev., 2016, 45, 2656; (j) Y. Li, D. J. Young and $\mathrm{X}$. J. Loh, Fluorescent gels: a review of synthesis, properties, applications and challenges, Mater. Chem. Front., 2019, 3, 1489; $(k)$ L. Xu, D. Zhang, T. K. Ronson and J. R. Nitschke, Improved Acid Resistance of a Metal-Organic Cage Enables Cargo Release and Exchange between Hosts, Angew. Chem., Int. Ed., 2020, 59, 7435; (l) Y.-X. Hu, X. Hao, L. Xu, X. Xie, B. Xiong, Z. Hu, H. Sun, G.-Q. Yin, X. Li, H. Peng and H.-B. Yang, Construction of Supramolecular Liquid-Crystalline Metallacycles for Holographic Storage of Colored Images, J. Am. Chem. Soc., 2020, 142, 6285; (m) D. H. Kim, N. Singh, J. Oh, E.-H. Kim, J. Jung, H. Kim and K.-W. Chi, Coordination-driven self-assembly of a molecular knot comprising sixteen crossings, Angew. Chem., Int. Ed., 2018, 57, 5669; ( $n$ ) D. Zhang, T. K. Ronson, L. Xu and J. R. Nitschke, Transformation Network Culminating in a Heteroleptic $\mathrm{Cd}_{6} \mathrm{~L}_{6} \mathrm{~L}_{2}$, Twisted Trigonal Prism, J. Am. Chem. Soc., 2020, 142, 9152; (o) A. J. McConnell, C. J. E. Haynes, A. B. Grommet, C. M. Aitchison, J. Guilleme, S. Mikutis and J. R. Nitschke, Orthogonal stimuli trigger self-assembly and phase transfer of $\mathrm{FeII}_{4} \mathrm{~L}_{4}$ cages and cargoes, J. Am. Chem. Soc., 2018, 140, 16952.

2 (a) M. Yoshizawa, J. K. Klosterman and M. Fujita, Functional molecular flasks: new properties and reactions within discrete, self-assembled hosts, Angew. Chem., Int. Ed., 2009, 48, 3418; (b) J. Zhu, X. Liu, J. Huang and L. Xu, Our expedition in the construction of fluorescent supramolecular metallacycles, Chin. Chem. Lett., 2019, 30, 1767; (c) K. Harris, D. Fujita and M. Fujita, Giant hollow $\mathrm{M}_{n} \mathrm{~L}_{2 n}$ spherical complexes: structure, functionalisation and applications, Chem. Commun., 2013, 49, 6703; (d) N. C. Gianneschi, M. S. Masar and C. A. Mirkin, Development of a coordination chemistry-based approach for functional supramolecular structures, Acc. Chem. Res., 2005, 38, 825; (e) D. L. Caulder and K. N. Raymond, Supermolecules by design, Acc. Chem. Res., 1999, 32, 975; (f) C. Xu, L. Xu and $\mathrm{X}$. Ma, A linear supramolecular polymer based on host-guest recognition and metal-ligand coordination, Chin. Chem. Lett., 2018, 29, 970; ( $g$ ) A. M. Castilla, W. J. Ramsay and J. R. Nitschke, Stereochemistry in subcomponent selfassembly, Acc. Chem. Res., 2014, 47, 2063; (h) G.-Y. Wu, L.-J. Chen, L. Xu, X.-L. Zhao and H.-B. Yang, Construction of supramolecular hexagonal metallacycles via coordinationdriven self-assembly: structure, properties and application, Coord. Chem. Rev., 2018, 369, 39; (i) L.-J. Chen and H.-B. Yang, Construction of stimuli-responsive functional materials via hierarchical self-assembly involving coordination interactions, Acc. Chem. Res., 2018, 51, 2699; $(j)$ W. Xue, Z. Di, Y. Zhao, A. Zhang and L. Li, DNA-mediated coordinative assembly of upconversion hetero-nanostructures for targeted dual-modality imaging of cancer cells, Chin. Chem. Lett., 2019, 30, 899; ( $k$ ) S. Fu, Q. Luo, M. Zang, J. Tian, Z. Zhang, M. Zeng, Y. Ji, J. Xu and J. Liu, Light-triggered reversible disassembly of stimuli-responsive coordination metallosupramolecular $\operatorname{Pd}_{2} \mathrm{~L}_{4}$ cages mediated by azobenzene-containing ligands, Mater. Chem. Front., 2019, 3, 1238; (l) L.-X. Cai, S.-C. Li, D.-N. Yan, L.-P. Zhou, F. Guo and Q.-F. Sun, Water-soluble redox-active cage hosting polyoxometalates for selective desulfurization catalysis, J. Am. Chem. Soc., 2018, 140, 4869; $(m)$ G. Li, Z. Zhou, C. Yuan, Z. Guo, Y. Liu, D. Zhao, K. Liu, J. Zhao, $\mathrm{H}$. Tan and X. Yan, Trackable supramolecular fusion: cage to cage transformation of tetraphenylethylene-based metalloassemblies, Angew. Chem., Int. Ed., 2020, 59, 10013; (n) J.-L. Zhu, L. Xu, Y.-Y. Ren, Y. Zhang, X. Liu, G.-Q. Yin, B. Sun, X. Cao, Z. Chen, X.-L. Zhao, H. Tan, J. Chen, X. Li and H.-B. Yang, Switchable Organoplatinum Metallacycles with High Quantum Yields and Tunable Fluorescence Wavelengths, Nat. Commun., 2019, 10, 4285; (o) L.-J. Chen, S. Chen, Y. Qin, 
L. Xu, G.-Q. Yin, J.-L. Zhu, F.-F. Zhu, W. Zheng, X. Li and H.-B. Yang, Construction of Porphyrin-Containing Metallacycle with Improved Stability and Activity within Mesoporous Carbon, J. Am. Chem. Soc., 2018, 140, 5049; (p) X. Yan, S. Li, T. R. Cook, X. Ji, Y. Yao, J. B. Pollock, Y. Shi, G. Yu, J. Li, F. Huang and P. J. Stang, Hierarchical self-assembly: well-defined supramolecular nanostructures and metallohydrogels via amphiphilic discrete organoplatinum(II) metallacycles, J. Am. Chem. Soc., 2013, 135 14036; (q) H. Ube, K. Endo, H. Sato and M. Shionoya, Synthesis of hetero-multinuclear metal complexes by siteselective redox switching and transmetalation on a homomultinuclear complex, J. Am. Chem. Soc., 2019, 141, 10384; (r) N. Singh, J.-H. Jo, Y. H. Song, H. Kim, D. Kim, M. S. Lah and K.-W. Chi, Coordination-driven self-assembly of an iridium-cornered prismatic cage and encapsulation of three heteroguests in its large cavity, Chem. Commun., 2015, 51, 4492; (s) A. J. McConnell, Spin-state switching in Fe(II) helicates and cages, Supramol. Chem., 2018, 30, 858.

3 (a) L. Xu, Y.-X. Wang and H.-B. Yang, Recent advances in the construction of fluorescent metallocycles and metallocages via coordination-driven self-assembly, Dalton Trans., 2015, 44, 867; (b) M. Lal Saha, X. Yan and P. J. Stang, Photophysical properties of organoplatinum(II) compounds and derived self-assembled metallacycles and metallacages: fluorescence and its applications, Acc. Chem. Res., 2016, 49, 2527; (c) D. R. Martir and E. Zysman-Colman, Photoactive supramolecular cages incorporating $\mathrm{Ru}(\mathrm{II})$ and $\operatorname{Ir}(\mathrm{III})$ metal complexes, Chem. Commun., 2019, 55, 139; (d) L. Ma, T. Yang, Z. Zhang, S. Yin, Z. Song, W. Shi, D. Chu, Y. Zhang and M. Zhang, Cyanostilbene-based near-infrared emissive platinum(II) metallacycles for cancer theranostics, Chin. Chem. Lett., 2019, 30, 1942; (e) W. Zheng, G. Yang, S.-T. Jiang, N. Shao, G.-Q. Yin, L. Xu, X. Li, G. Chen and H.-B. Yang, A tetraphenylethylene (TPE)-based supraamphiphilic organoplatinum(II) metallacycle and its selfassembly behaviour, Mater. Chem. Front., 2017, 1, 1823; $(f)$ C.-L. Liu, R.-L. Zhang, C.-S. Lin, L.-P. Zhou, L.-X. Cai, J.-T. Kong, S.-Q. Yang, K.-L. Han and Q.-F. Sun, Intraligand charge transfer sensitization on self-assembled europium tetrahedral cage leads to dual-selective luminescent sensing toward anion and cation, J. Am. Chem. Soc., 2017, 139, 12474; (g) C.-B. Huang, L. Xu, J.-L. Zhu, Y.-X. Wang, B. Sun, X. Li and H.-B. Yang, Real-Time Monitoring the Dynamics of Coordination-Driven Self-Assembly by Fluorescence-Resonance Energy Transfer, J. Am. Chem. Soc., 2017, 139, 9459; (h) X. Yan, P. Wei, Y. Liu, M. Wang, C. Chen, J. Zhao, G. Li, M. L. Saha, Z. Zhou, Z. An, X. Li and P. J. Stang, Endo- and exo-functionalized tetraphenylethylene $\mathrm{M}_{12} \mathrm{~L}_{24}$ nanospheres: fluorescence emission inside a donfined space, J. Am. Chem. Soc., 2019, 141, 9673; (i) T. Nakamura, H. Ube, R. Miyake and M. Shionoya, A $\mathrm{C}_{60}$-templated tetrameric porphyrin barrel complex via zinc-mediated self-assembly utilizing labile capping ligands, J. Am. Chem. Soc., 2013, 135, 18790.

4 (a) S. Shanmugaraju and P. S. Mukherjee, $\pi$-Electron rich small molecule sensors for the recognition of nitroaromatics,
Chem. Commun., 2015, 51, 16014; (b) T. M. Figueira-Duarte and K. Müllen, Pyrene-based materials for organic electronics, Chem. Rev., 2011, 111, 7260; (c) M. A. Winnik and F. M. Winnik, Fluorescence studies of polymer association in water, Adv. Chem. Ser., 1993, 485; (d) F. M. Winnik, Photophysics of preassociated pyrenes in aqueous polymer solutions and in other organized media, Chem. Rev., 1993, 93, 587; (e) X.-D. Xu, J. Zhang, X. Yu, L.-J. Chen, D.-X. Wang, T. Yi, F. Li and H.-B. Yang, Design and preparation of platinum-acetylide organogelators containing ethynyl-pyrene moieties as the main skeleton, Chem. - Eur. J., 2012, 18, 16000; $(f)$ J. Zhu, P. Jia, N. Li, S. Tan, J. Huang and L. Xu, Small-molecule fluorescent probes for the detection of carbon dioxide, Chin. Chem. Lett., 2018, 29, 1445; ( $g$ ) S. Long, W. Chi, L. Miao, Q. Qiao, X. Liu and Z. Xu, Strong $\pi-\pi$ stacking interactions led to the mis-assignment of dimer emissions to the monomers of 1-acetylpyrene, Chin. Chem. Lett., 2019, 30, 601; (h) X. Song, J. Zhao, W. Zhang and L. Chen, Novel n-channel organic semiconductor based on pyrene-phenazine fused monoimide and bisimides, Chin. Chem. Lett., 2018, 29, 331; (i) N.-W. Wu, J. Zhang, C.-H. Wang, L. Xu and H.-B. Yang, Synthesis and characterization of multipyrene-modified platinum acetylide oligomers, Monatsh. Chem., 2013, 144, 553; $(j)$ Z. Li, Y. Li, D. Wang, Q. Cui, Z. Li, L. Wang and H. Yang, Unique fluorescence properties of a self-assembling bis-pyrene molecule, Chin. Chem. Lett., 2018, 29, 1645; (k) Z.-Y. Li, L. Xu, C.-H. Wang, X.-L. Zhao and H.-B. Yang, Novel platinum-acetylide metallocycles constructed via a stepwise fragment coupling approach and their aggregation behaviour, Chem. Commun., 2013, 49, 6194; (l) N.-W. Wu, J. Zhang, X.-D. $\mathrm{Xu}$ and H.-B. Yang, Design and preparation of ethynyl-pyrene modified platinum-acetylide gelators and their application in dispersion of graphene, Chem. Commun., 2014, 50, 10269; (m) S. Long, Q. Qiao, L. Miao and Z. Xu, A self-assembly/ disassembly two-photo ratiometric fluorogenic probe for bacteria imaging, Chin. Chem. Lett., 2019, 30, 573.

5 (a) J. B. Birks, Photophysics of aromatic molecules, WileyInterscience, London, 1970; $(b)$ K. Kalyanasundaram and J. K. Thomas, Environmental effects on vibronic band intensities in pyrene monomer fluorescence and their application in studies of micellar systems, J. Am. Chem. Soc., 1977, 99, 2039; (c) S. Cicchi, P. Fabbrizzi, G. Ghini, A. Brandi, P. Foggi, A. Marcelli, R. Righini and C. Botta, Pyrene-excimers-based antenna systems, Chem. - Eur. J., 2009, 15, 754; (d) Y. Ohishi and M. Inouye, Circularly polarized luminescence from pyrene excimers, Tetrahedron Lett., 2019, 60, 151232.

6 (a) F. Würthner and A. Sautter, Energy transfer in multichromophoric self-assembled molecular squares, Org. Biomol. Chem., 2003, 1, 240; (b) A. Sautter, B. K. Kaletaş, D. G. Schmid, R. Dobrawa, M. Zimine, G. Jung, I. H. M. van Stokkum, L. De Cola, R. M. Williams and F. Würthner, Ultrafast energy-electron transfer cascade in a multichromophoric light-harvesting molecular square, J. Am. Chem. Soc., 2005, 127, 6719; (c) C.-C. You, C. Hippius, M. Grüne and F. Würthner, Light-harvesting metallosupramolecular squares composed of perylene bisimide walls and fluorescent antenna dyes, Chem. - Eur. J., 2006, 12, 7510. 
7 N.-W. Wu, J. Zhang, D. Ciren, Q. Han, L.-J. Chen, L. Xu and H.-B. Yang, Construction of supramolecular pyrene-modified metallacycles via coordination-driven self-assembly and their spectroscopic behavior, Organometallics, 2013, 32, 2536.

8 M. He, Q. Han, J. He, Q. Li, Z. Abliz, H. Tan, L. Xu and H. Yang, Self-assembly of pyrene-modified rhomboidal metallodendrimers via directional metal-ligand bonding approach, Chin. J. Chem., 2013, 31, 663.

9 S. Kobayashi, M. Lal Saha and P. J. Stang, Pyrene functionalized metallosupramolecular rhomboids and their photophysical properties, J. Organomet. Chem., 2017, 847, 294.

10 X. Chang, Z. Zhou, C. Shang, G. Wang, Z. Wang, Y. Qi, Z.-Y. Li, H. Wang, L. Cao, X. Li, Y. Fang and P. J. Stang, Coordination-driven self-assembled metallacycles incorporating pyrene: fluorescence mutability, tunability, and aromatic amine sensing, J. Am. Chem. Soc., 2019, 141, 1757.

11 B. Shi, Y. Liu, H. Zhu, R. T. Vanderlinden, L. Shangguan, R. Ni, K. Acharyya, J.-H. Tang, Z. Zhou, X. Li, F. Huang and P. J. Stang, Spontaneous formation of a cross-linked supramolecular polymer both in the solid state and in solution, driven by platinum(II) metallacycle-based host-guest interactions, J. Am. Chem. Soc., 2019, 141, 6494.

12 (a) P. Wei, X. Yan and F. Huang, Supramolecular polymers constructed by orthogonal self-assembly based on hostguest and metal-ligand interactions, Chem. Soc. Rev., 2015, 44, 815; (b) Y. Sun, C. Chen, J. Liu and P. J. Stang, Recent developments in the construction and applications of platinum-based metallacycles and metallacages via coordination, Chem. Soc. Rev., 2020, 49, 3889; (c) G.-Z. Zhao, L.-J. Chen, W. Wang, J. Zhang, G. Yang, D.-X. Wang, Y. Yu and H.-B. Yang, Stimuli-responsive supramolecular gels through hierarchical self-assembly of discrete rhomboidal metallacycles, Chem. - Eur. J., 2013, 19, 10094; (d) Z.-Y. Li, Y. Zhang, C.-W. Zhang, L.-J. Chen, C. Wang, H. Tan, Y. Yu, X. Li and H.-B. Yang, Cross-linked supramolecular polymer gels constructed from discrete multi-pillar[5]arene metallacycles and their multiple stimuli-responsive behavior, J. Am. Chem. Soc., 2014, 136, 8577; (e) W. Zheng, L.-J. Chen, G. Yang, B. Sun, X. Wang, B. Jiang, G.-Q. Yin, L. Zhang, X. Li, M. Liu, G. Chen and H.-B. Yang, Construction of smart supramolecular polymeric hydrogels cross-linked by discrete organoplatinum(II) metallacycles via post-assembly polymerization, J. Am. Chem. Soc., 2016, 138, 4927.

13 (a) M. Poyatos, J. A. Mata and E. Peris, Complexes with poly(N-heterocyclic carbene) ligands: structural features and catalytic applications, Chem. Rev., 2009, 109, 3677; (b) E. Peris, Smart N-heterocyclic carbene ligands in catalysis, Chem. Rev., 2018, 118, 9988.

14 V. Martínez-Agramunt, S. Ruiz-Botella and E. Peris, Nickelcornered molecular rectangles as polycyclic aromatic hydrocarbon receptors, Chem. - Eur. J., 2017, 23, 6675.
15 V. Martínez-Agramunt, T. Eder, H. Darmandeh, G. GuisadoBarrios and E. Peris, A size-flexible organometallic box for the encapsulation of fullerenes, Angew. Chem., Int. Ed., 2019, 58, 5682 .

16 V. Martínez-Agramunt and E. Peris, Photocatalytic properties of a palladium metallosquare with encapsulated fullerenes via singlet oxygen generation, Inorg. Chem., 2019, 58, 11836.

17 V. Martínez-Agramunt and E. Peris, A palladium-hinged organometallic square with a perfect-sized cavity for the encapsulation of three heteroguests, Chem. Commun., 2019, 55, 14972.

18 S. Ibáñez and E. Peris, Dimensional matching versus induced-fit distortions: binding affinities of planar and curved polyaromatic hydrocarbons with a tetragold metallorectangle, Angew. Chem., Int. Ed., 2020, 59, 6860.

19 (a) R. Chakrabarty and P. J. Stang, Post-assembly functionalization of organoplatinum(II) metallacycles via copperfree click chemistry, J. Am. Chem. Soc., 2012, 134, 14738; (b) B. Eggers and U. Ziener, Optically functionalized gridtype complexes by a post-assembly strategy, Chem. - Eur. J., 2018, 24, 14968.

20 Y. Wang, Y. Gu, E. G. Keeler, J. V. Park, R. G. Griffin and J. A. Johnson, Star polyMOCs with diverse structures, dynamics, and functions by three-component assembly, Angew. Chem., Int. Ed., 2017, 56, 188.

21 P. P. Neelakandan, A. Jiménez and J. R. Nitschke, Fluorophore incorporation allows nanomolar guest sensing and white-light emission in $\mathrm{M}_{4} \mathrm{~L}_{6}$ cage complexes, Chem. Sci., 2014, 5, 908.

22 S. Shanmugaraju, H. Jadhav, Y. P. Patil and P. S. Mukherjee, Self-assembly of an octanuclear platinum(II) tetragonal prism from a new $\mathrm{Pt}_{4}{ }^{\mathrm{II}}$ organometallic star-shaped acceptor and its nitroaromatic sensing study, Inorg. Chem., 2012, 51, 13072.

23 B.-B. Guo, W.-X. Gao, Y.-J. Lin and G.-X. Jin, Construction of half-sandwich multinuclear complexes including tunnel architectures via $\mathrm{C}-\mathrm{H}$-activation-directed assembly, Dalton Trans., 2018, 47, 7701.

24 V. Martínez-Agramunt, D. G. Gusev and E. Peris, A shapeadaptable organometallic supramolecular coordination cage for the encapsulation of fullerenes, Chem. - Eur. J., 2018, 24, 14802.

25 T. K. Ronson, A. B. League, L. Gagliardi, C. J. Cramer and J. R. Nitschke, Pyrene-edged $\mathrm{Fe}_{4}{ }^{\mathrm{II}} \mathrm{L}_{6}$ cages adaptively reconfigure during guest binding, J. Am. Chem. Soc., 2014, 136, 15615.

26 T. K. Ronson, W. Meng and J. R. Nitschke, Design principles for the optimization of guest binding in aromatic-paneled $\mathrm{Fe}_{4}{ }^{\mathrm{II}} \mathrm{L}_{6}$ cages, J. Am. Chem. Soc., 2017, 139, 9698.

27 T. K. Ronson, D. A. Roberts, S. P. Black and J. R. Nitschke, Stacking interactions drive selective self-assembly and selfsorting of pyrene-based $\mathrm{M}_{4}{ }^{\mathrm{II}} \mathrm{L}_{6}$ architectures, J. Am. Chem. Soc., 2015, 137, 14502. 